\title{
A Suggested E-Tutor Model As Dynamic Intelligent Tutoring System For Mathematics in Egyptian Language Schools
}

\author{
Safaa S. Mahmoud
}

\begin{abstract}
Current research aimed to construct an e-tutor according to Dynamic Math Intelligent Tutoring System (MD_ITS) to help mathematics teachers to develop their e-courses, and their Knowledge Base according to e-tutor algorithm and instructional design. A sample of teachers from Taha Hussein Language school, Yarmouk School, Mohammad Najibullah experimental language schools were chosen, The sample is divided into two equal groups: the first experimental group was taught Math Fractions units to fourth grade students of primary schools through the proposed e-tutor software designed in accordance with the intelligent tutoring system (MD_ITS), and the other experimental group was taught by the traditional software prepared by the Ministry of Education. Then the test measurements of Math teachers attitudes towards e-courses depended on ITS were applied. The proposed intelligent (MD_ITS) design, depended on some instructional models. Researcher adopted the model of the " Fogan Tai, 1994" including phases of: analysis phase, instructional design phase, Interaction design phase, production phase. Also addressed the study of the (Rezzaq, 2003) to design a system, based on smart dialogue, to improve the level of student performance as a tool to provide content.
\end{abstract}

The suggested E-tutor MD-ITS depends on the four sub-models:

1) Expert Model, to extract knowledge and representation.

2) Student Model, to determine the student's knowledge to provide intelligent problem of the child.

3) Tutorial Model, to choose the appropriate lesson for the child, depending on the response model. ITS can offer the guidance, hints, help, and assistance.

4) User Interface, The interaction between the user (both teacher and students) and the system.

The proposed E-Tutor MD_ITS activate the role of a teacher and involvement him in the development of lessons, questions, guidance, assistance generated for the responsibility towards the students, and created a kind of competition among teachers to try to access to the most basic formulas, which would simplify the subject and therefore it was to benefit from their experiences as experts in area of specialization, also encouraged teachers to enter data and information, which in turn directly to the dynamics of knowledge bases built by the researcher.

Keywords: ITS, instructional Design, e-tutor, AI, intelligent software, MD_ITS (Math Dynamic Intelligent Tutoring System.

\section{INTRODUCTION}

This century has been characterized by scientific progress and the accompanying scientific research and the explosion of knowledge and accompanied by a magnitude of information generated daily, which led to a multiplicity of actions, which changed the patterns of life (AlFar,2000). There are many studies, in the fields of education, knowledge of psychology, and artificial intelligence, such as studies which concentrated on the application of artificial intelligence technology, engineering and technology in the systems (CAI), which led to the emergence of an integrated educational systems, called intelligent computer assisted Instructions (ICAI), it showed that the computer systems that contain artificial intelligence have the capacity to do the work of teaching in specific areas, whereupon the software traditional to address the following shortcomings: (Ong, 2000)

- Inability to dialogue with the students of natural language.

- Inability to understand the Subject Being Taught and does not accept responses or unexpected questions.

- They present correct answer only with some alternatives, (one answer correct and the other wrong), only the student chooses the answer without reference to the details of the solution steps.

- There are no steps to resolve the problems.

- Inability to decide what the student will study later.

The study of Slavomir and et al (2007) concentrated on the Intelligent systems that are have smart classes of e-learning environment, which is a teaching and learning developed to adapt with the individual characteristics of the learner, the structures of the author (Authoring shells) with their environment, which allows the systems to be intelligent education development. The study concentrated on the implementation and development of those systems and structures of their own copyright and Surveys have confirmed the effectiveness of education systems and smart structures in various stages of learning starting from the stage of basic education to the academic level.

Some studies also confirmed that the traditional education systems are not developed innovative thinking of the child in general and in mathematics in particular, as they do not cooperate in improving the teacher's teaching methods(Saleh, 2002).

The Exploratory study has shown that by the status of the educational software within the Egyptian schools are:

1) Survey confirmed the view of the Math teachers at the primary schools who use the computer in teaching and use the current available software is 
offered by the Ministry of Education. They confirmed that the traditional S/W do not have the properties of intelligent software

2) Most Math teachers in Primary Language school do not have any background on inteligent Tutoring systems.

3) The choice of suitable software for children from 7-12 years old is critical for this stage in terms of their relevance with the children's capacities to deal with them. The available $\mathrm{S} / \mathrm{W}$ in the market now has some good software, and some very poor in content and low level of the intended software in general.

A. Research Problem: The main problem of research is shown in the following question:

"What is the effectiveness of the proposed e-tutor on the development of dynamic, Math intelligent tutoring system (MD_ITS) for mathematics teachers in languages schools and their attitudes towards e- course?". This main question divided into sub-questions, the are:

1- What are the different phases for building a dynamic e-tutor as intelligent Tutoring System?

2- What are the Effectiveness of a dynamic inteligent Tutoring system on the attitudes direction of mathematics teachers in languages schools towards e- course?

\section{B. Research Objectives: Current research has aimed to} achieve the following objectives:

- Development an intelligent e-tutor educational system for mathematics in English used in Languages school.

- Construction of instructional Design model to be the base of dynamic intelligent Tutoring System that help mathematics teachers to develop their e-courses in effective electronic flexible and compose the required Knowledge Base.

\section{The Importance of Research: The current research may contribute in:}

- Study the possibility of using (e-tutor based ITS) with teacher at the primary level.

- Provide intelligent software to help in teaching children to acquire some of the concepts of Math.

- Encourage the design of software based on ITS to convert the children course in various educational materials in the light of the outcome of the research results.

- Identify the effective design model for building a software system based on intelligent tutoring system for primary schools.

- Change the attitudes of teachers towards the use of e-courses and e-tutor in the educational process.

\section{The Limits of Research:}

Current research is limited to a group of mathematics teachers in primary languages schools:

- Taha Hussein Language school(El

Materaia-management area),Yarmouk School,

Mohammad Najibullah Experimental languages

school(Al America- Alexandria).

- Content of proposed e-tutor DMITS (Dynamic Math Intelligent Tutoring System ) was limited by the Fractions units of mathematics course which is taught to fourth grade of primary schools.

E. Research Hypothesis: Current research is to verify the authenticity of the following hypothesis:

There is no statistically significant at the level of (0.01) between the attitudes of Math teachers between the first experimental group (who use the Traditional Math Software settled by Ministry of Education) and the second experimental group (who used the proposed e-tutor as a dynamic intelligent Tutoring System), in favor of experimental group II.

\section{F. Research Methodology: This research used two} approaches:

1- Descriptive approach: to describe and analyze the research, studies and previous literature.

2- Experimental approach: to study the impact of the proposed E-Tutor MD_ITS to the direction of the development of mathematics teachers at the primary stage towards e-tutor MDITS to detect the relationship between the following variables:

- The Independent Variable:

- Dynamic intelligent tutoring system, and - Traditional Software.

- The Dependent Variables: the direction of mathematics teachers towards the use of e-tutor MD_ITS designed.

\section{[1] Research Sample:}

A sample of (10) Math teachers of some experimental language schools were divided into two groups. The strength of each group (5) teachers have been selected by teachers who meet the conditions of the sample (good use of computer in teaching).

\section{[2] Experimental Design:}

Experimental design depended on two processing, the first pilot research group(who taught the content of fractions through the traditional software processing), while the second group who taught Math with the proposed e-tutor MDITS containing fractions units. The experimental design used is known as the global design $1 \times 2$ as shown in table 1

Table (1): Experimental Design For The Research Variables

\begin{tabular}{r|c|c}
\hline The & Traditional & Intelligent \\
dependent & software & dynamic \\
variables & Settled by & software \\
& Ministry of & education \\
Independent & Education & e-tutor \\
variables & & MD_ITS \\
\hline \hline
\end{tabular}




\begin{tabular}{|c|c|c|}
\hline Direction & $\begin{array}{l}\text { Measurement } \\
\text { of Directions } \\
\text { towards } \\
\text { using } \\
\text { traditional } \\
\text { programming }\end{array}$ & $\begin{array}{l}\text { Measurement } \\
\text { of Direction } \\
\text { towards using } \\
\text { dynamic } \\
\text { e-tutor } \\
\text { intelligent } \\
\text { software }\end{array}$ \\
\hline
\end{tabular}

G. Research Procedures: There are some procedures which can be summarized in the following steps:

1) Review of studies and references associated with the field of research to formulate a theoretical framework.

2) analyzed the content of Math book of Education Ministry of a primary school.

3) Select some of the Math concepts in light of the suggested e-course through arbitration and a group of professors and experts of the primary selection of the most linked to these concepts in the scientific content.

4) Preparation of the Intelligent Tutoring system scenario e-tutor based on MDITS, which have been achieved through the educational objectives in the light of the experience of teachers to that stage.

5) Building inteligent Tutoring system (E-TUTOR MD_ITS), in light of Professor of arbitrators in the field of education, psychology, technology, education and computers.

6) Build the proposed intelligent (MD_ITS) design, depended on some instructional models. Researcher has adopted the model of the " Fogan Tai, 1994" including phases of: analysis phase, instructional design phase, Interaction design phase, production phase. Also addressed the study of the (Rezzaq, 2003) to design e-tutor, based on smart dialogue, to improve the level of student performance as a tool to provide content.

7) The division of the sample into two equal groups, one of the first pilot (use a software interface designed inteligent Tutoring system (E-TUTOR MD_ITS), the second pilot use the software developed by the Ministry of Education).

8) The application of research experience (use intelligent e-tutor DMITS )to have been taken into account the timing of the consolidation of the teaching of teachers in both groups.

9) The application of a test to measure the teacher attitude towards electronic course on both groups. to obtain the results of measuring the direction towards the e-tutor of the two pilot electronic I and II.

10) Statistical data processing.

11) Presentation of results and discussion and interpretation, and recommendations.

\section{THEORETICAL FRAMEWORK}

\section{A. Artificial Intelligence and its Applications in The Educational Process:}

There are a lot of attempts to understand human intelligence and artificial intelligence and theories associated with each of them, there are also attempts to understand and interpret models of intelligence, whether naturally or artificially. Through the analysis, design and evaluate the performance of computers and the identification of many different aspects of intelligence such as: the ability to classify the models and the capacity for logical reasoning based on rational thinking and learning experience(Honaver, 2005). AI Artificial Intelligence is a serious effort to try to understand the human experience with some of the complex role in the process of information processing. In other words, the artificial intelligence does not deal only with how to display and use of information and complex forms of non-integrated in accordance with the rules of logical thinking, but also deals with some questions about how he sees the (vision) and moving (automatic), and communication (natural language and speech)(Barber,2002).

The most distinctive feature is the artificial intelligence methodology to achieve its objectives in the mental capacity to understand the human person, based on the simulation, through the writing of computer programs and noting the behavior of such programs and modification (Tolba, 2002).

\section{B. The Artificial Intelligence Objects:}

The Artificial intelligence Objects are understanding of all the senses used for logical thinking, innovation, creativity, education and linguistic processes. It is necessary to understand without a doubt in the usefulness and effectiveness of the design and construction of new tools have proven effective in such diverse areas as education, industry, culture, and such useful inventions effective recall mobile forces, including the invention of trains and the development of the aircraft, which made us go through the long distances quickly, and gave us a means of movement and transition, and has led research in the field of artificial intelligence to provide tools that enrich the innovation and creativity and increase the capacity of the human cultural and mental (Abu-Ata, 2004).

The different technologies used in the construction of many artificial intelligence programs, differ from those used in traditional Software programs, in many aspects as: storage, retrieval, these differences are in the following table (Abu-Ata, 2004). Intelligent is the ability to acquire and use knowledge and the ability to think. knowledge consists of a set of facts, concepts, theories, rules on a specific problem to be resolved in addition to the outcome of the experience of experts in the field, which contains the problem. Salem (2001)classified the perspective of artificial intelligence to the knowledge of two types:

A - Constant Knowledge: The facts and information that do not change with time, things are correct and realistic.

B - Episodic Knowledge (a changing knowledge): 
Knowledge is change with time, that is, formed by the acquisition of expertise in a particular area it is knowledge acquired from exposure to the events and attitudes of human exposure. The most applications of artificial intelligence (A1) knowledge Processing which is part of the subject of so-called Knowledge Engineering.

Table (2): The Difference Between Artificial Intelligence Programs and Traditional S/W Programs

\begin{tabular}{|c|c|c|}
\hline $\begin{array}{c}\text { In } \\
\text { Comparison }\end{array}$ & $\begin{array}{c}\text { Artificial } \\
\text { intelligence } \\
\text { Programming }\end{array}$ & $\begin{array}{c}\text { Traditional } \\
\text { Programming }\end{array}$ \\
\hline Inputs & Knowledge & $\begin{array}{c}\text { Data and } \\
\text { information }\end{array}$ \\
\hline Input nature & $\begin{array}{c}\text { Deal with inputs } \\
\text { unclear or } \\
\text { incomplete }\end{array}$ & $\begin{array}{l}\text { Required to be } \\
\text { clear and } \\
\text { complete }\end{array}$ \\
\hline Search input & $\begin{array}{c}\text { Exploratory \& } \\
\text { Heuristic }\end{array}$ & Algorithm \\
\hline $\begin{array}{c}\text { The nature of } \\
\text { processing }\end{array}$ & Symbolic & Numeric \\
\hline $\begin{array}{l}\text { The Quality } \\
\text { of Processing }\end{array}$ & $\begin{array}{l}\text { Knowledge } \\
\text { Processing of } \\
\text { the Inference } \\
\text { Engine }\end{array}$ & Data processing \\
\hline $\begin{array}{c}\text { Explanation } \\
\& \\
\text { Interpretatio } \\
\mathbf{n}\end{array}$ & $\begin{array}{l}\text { Required to give } \\
\text { an explanation } \\
\text { and } \\
\text { interpretation of } \\
\text { the solutions and } \\
\text { results }\end{array}$ & $\begin{array}{l}\text { Often not given } \\
\text { an explanation } \\
\text { and interpretation } \\
\text { of the solutions } \\
\text { and results }\end{array}$ \\
\hline $\begin{array}{l}\text { Difficult and } \\
\text { Complex } \\
\end{array}$ & $\begin{array}{c}\text { Easy and } \\
\text { flexible } \\
\end{array}$ & $\begin{array}{c}\text { Difficult and } \\
\text { complex }\end{array}$ \\
\hline $\begin{array}{c}\text { Areas of } \\
\text { Application }\end{array}$ & $\begin{array}{l}\text { Specialized } \\
\text { areas such as: } \\
\text { diagnosis, } \\
\text { treatment, } \\
\text { problem } \\
\text { solving, } \\
\text { machine } \\
\text { translation, to } \\
\text { identify the } \\
\text { images and } \\
\text { shapes, and } \\
\text { voice } \\
\text { recognition }\end{array}$ & $\begin{array}{l}\text { Simple general } \\
\text { areas such as: } \\
\text { accounts, storage, } \\
\text { retrieval, simple } \\
\text { control. }\end{array}$ \\
\hline
\end{tabular}

\section{Natural of Knowledge Representation:}

It is known in the field of artificial intelligence, cognitive science and knowledge are represented in the light pattern and in which there are significant efforts in the field of artificial intelligence to discover ways to gain this knowledge and the collection and coding (encoding and encrypted) that its relevance for use by machine, thus turning it into a set of orders such as the use of language (Prolog - LISP).

The identification of the key role played by the knowledge representations is essential to understanding and engineering of intelligence and understanding of the nature of the representations that exist between the issues and questions in the field of artificial intelligence, and cognitive science. The most common way is to use knowledge representations logic is a simple way to represent the knowledge (and to some extent can be viewed as a logic level of the post-knowledge and how to represent the development of knowledge).

\section{Components of Knowledge Engineering Process}

1) Knowledge engineering process includes five activities can be summarized as follows:(Salem, 2001).

2) Knowledge Acquisition: This activity includes the acquisition of knowledge from experts, books, documents, instruments or sensors or computer files, and can describe the knowledge to fit the scope of a particular problem, and methods of procedure to solve this problem.

3) Knowledge representation: the knowledge gained to be regulated process known as knowledge representation, which includes the preparation of the way of knowledge (Knowledge Map) encryption and the resolution of existing knowledge in the knowledge base.

4) Knowledge Validation: to verify that the knowledge is correct and the existing knowledge base is valid using the (Test Cases) to reach acceptable quality.

5) Inference: This activity includes the design of computer software that can be inferred from the conduct based on knowledge and advice to the user in a particular subject.

6) Explanation and Justification: This activity includes the design and programming capacity to explanation. For example: the ability to program the answer to questions such as Why does the computer to certain information? How can access to a certain conclusion through the computer? Could represent the activities of engineering knowledge and the relations between these activities, by the figure (1):

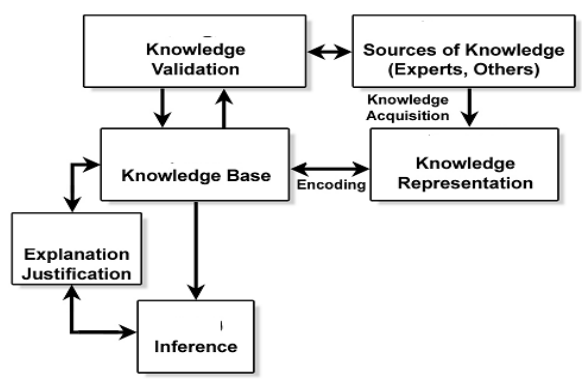

Figure (1): The Activities of Knowledge Engineering and the Relationships Between Them Tolba et al, 2002

\section{INTELLIGENT TUTORING SYSTEMS APPLICATIONS IN THE} EDUCATIONAL PROCESS:

\section{A. Definition of Intelligent Tutoring Systems :There are many definitions, some of the definitions are:}

Broadly,(2005) define the intelligent Tutoring systems include a component of artificial intelligence. This software tracks the student's level and adjust it with the feedback signals to provide hints on the level throughout the period of 
study of those systems, and can work inferences about the strengths and weaknesses and can propose activities and additional work by compiling information on the performance of each student. Ong James, (2003) showed that applying artificial intelligence techniques to adapt to individual learners in both the subject to be learned and the manner or method of learning appropriate to each learner or student. The intelligent systems in the opinion of Wegerif, 2005(Wegerif,2005) is the link between behavioral learning and computer-based cognitive. Artificial intelligence research is characterized as intelligent as they reflect and represent the area to be learned models, models of the students and the teacher Expert Tutor) to this area. The design of intelligent Tutoring systems (ITS) that there is an initial and primary concerns of the teaching process to identify and decide what should be taught - and what teaching strategies should be used - what are the stages and the sequential steps of the process of teaching to facilitate the learning process, and without a doubt that all these functions are necessary of the process of teaching, however, that there is the educational aspect, which should not be ignored, where the learners knowledge background, and the individual needs of different groups of learners, therefore, must be the importance of planning learning process.

\section{B. The Objective of Intelligent Tutoring system}

The objective of intelligent Tutoring system is to provide intelligent e-learning based on learning step by step and effective experience, such as training and simulation, the intelligent Tutoring system enable participants to require them to practice their skills during the performance of the interactive learning environments. The intelligent Tutoring system to respond to the questions of users and provide them with guidance on the individual and technologies other than computer-based training and the development of a model student, the education systems of smart strategies to harmonize education in both content and style, working on the supply of students with explanations and examples and references, and training to solve the problems of education as required by the position (Ong, and Ramachandran, 2000).

The intelligent Tutoring system (ITS) contribute significantly to the treatment of many problems in the educational process, such as a lack of capacity and lack of specialists and school staff and the large number of learners ... And others, in this light that can determine the educational objectives of those systems to increase capacity between the interactive and interactive student-teaching program, through natural language dialogue for students, and respond to questions and queries in the different educational content, and the generation of explanations and clarifications necessary to explain the solutions and products that have been reached.

\section{Literature Review of Intelligent Tutoring System}

Study of (Kerly \& Ellis, 2008), where they have to build a system that integrates natural language techniques, to address the database and learning theories in light of the negotiated learner model of a Negotiated (Hear Men Model) and for the integration of the education system with intelligent system gives the learner the opportunity to compare the on and capacity to learn with those deduced by the system, the system provides also a conversation, or the so-called "Chat bot", which was developed to allow the speaker to negotiate or debate with the use of natural language, and it is the most important objectives of the system knowledge to support the objectives of the Meta Cognitive self-assessment reaction. The present report on the user's system and have found a natural language conversation, to increase the accuracy of self-evaluation of the students themselves, and reduce the number of discrepancies between the system and user beliefs negotiated learner model.

The diverse uses of intelligent Tutoring system in various scientific fields and in the following we review some of those studies to illustrate the wide range of uses (ITS) in various areas:

The study and of (Stotter, \& Domeshek, 2005) is to improve the performance of war fighters which found that such systems provide many benefits to meet the training needs of the army such as the use of explanations based on the simulation of the actual reality, and the interest of such systems for military purposes of the assessment the capacity of student performance and the decision to provide him with feedback and strengthen the abilities and combat skills, and formulate plans for teaching to meet the individual needs of students. The study confirmed that the relevance and efficiency of education systems in the smart training military students and recommended the need to develop appropriate training plans tailored to the needs and capabilities of the trainee and the development of teaching strategies in the light of the skills and abilities of students in the light of their differences during the training process and the importance of the integration of simulation in the training process.

In a study of Al-Sheikh, (2002), entitled "A new system for the generation of intelligent Tutoring system to re-use of components and systems, knowledge-based". This study has provided integrated systems of education which integrates intelligent tutoring system and the experience system based on a set of skills and information to teach (Excel)program in order to be eligible for re-use of those skills and information for educational purposes as it allows for different teachers use to solve the problems faced by the consultancy of expert system in order to be used in addition to education and training through the education system intelligent. The results of the evaluation of such importance in the system to provide educational system through the intelligent expert systems, as well as a practical guide for the possibility of re-use of knowledge stored for more than a goal within a system of knowledge stored.

The study of the (Rezzaq, 2003) is addressed to design a system launched by the name of the "E-Tutor", which tried the comparison of education systems based on smart dialogue, and others does not depend on the dialogue, and focused in the study to demonstrate the importance of dialogue Educational Tutorial Dialog to improve the level of student performance . 
IV. THE SugGested E-TUTOR MOdel ACCORDING TO DYNAMIC INTELLIGENT TUTORING INSTRUCTIONAL DESIGN FOR MATHEMATICS IN EGYPTIAN LANGUAGE SCHOOLS

\section{A. The Objective of Building the e-tutor in Egyptian language schools :}

The aim of the dynamic tutoring system which is a much more intelligent prepared to achieve the following:

- Study the possibility of using (ITS) with children at the primary level.

- Provide an intelligent software to help teach children to acquire some of the concepts of Math.

- Encourage to design software systems for children in various educational materials in the light of the outcome of the research results.

- Change the attitudes of teachers towards the use of e-courses in the educational process.

The construction of any system of education must follow the specific model of design education, which is perceived as just a mental description of procedures and processes for the design and development of education, and their representation, in a simplified manner, in written form, provides a guiding framework for such operations, relations and understanding, organization, interpretation and modification, and the discovery of relationships and information of new and unpredictable results (Khamis, 2003).

\section{B. The Instructional Design Model of the Proposed MDITS:}

The proposed intelligent (MD_ITS) design, depended on some instructional models. Researcher adopted the model of the "Fogan Tai, 1994" including phases of: analysis phase, instructional design phase, Interaction design phase, production phase. Also addressed the study of the (Rezzaq,2003) to design a system, based on smart dialogue, to improve the level of student performance as a tool to provide content as shown in Fig (2). Researcher adopted the model of the "Fogan Tai, 1994" for the design and development of the dynamic design of intelligent education system, the replace the current study, researcher have followed the following steps, respectively, in the intelligent building system (analysis phase - the design phase - the development phase - the Implementation phase and evaluation phase), as a model all phases of a comprehensive design and educational development, as characterized by flexibility and mutual influence between the elements of this model is consistent with the logical steps of planning, preparation and design of computer presentations and high-multiple media, and this model has proven its effectiveness in the current research in conjunction of dialogue system.

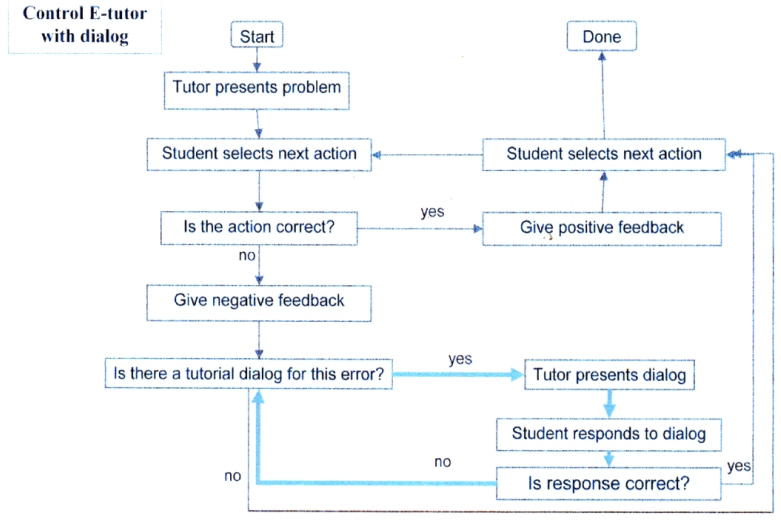

Figure (2): System Architecture shows the E-tutor with Student Dialogue (Rezzaq, 2003)

It was obvious to the researcher, this model is the most appropriate models of the design and educational development of the educational system, the proposed intelligent (MD_ITS), and the following figure shows the model of Fogan Thai, which is used in the design and production of educational computer programs, with some minor modifications with the nature of education systems, and Smart, which depends on the hypermedia, as a tool to provide content.

The design and implementation of an e-tutor intelligent Tutoring system for mathematics in English, it is functionally the intelligent Tutoring system that it contains all the human teacher should do: the choice of appropriate educational material for each student, to provide the student exercise, control the activity of the student, to give students references and suggestions during the exercises, feedback all time, to understand why students make mistakes, explain the different methods of teaching used with the various students and ask students to answer questions, and we have a much more careful when designing the MDITS the characteristics of the intelligent and has been launched by the name of e-Tutor MDITS .

\section{The Dynamic Knowledge Base Used in the Construction of The Proposed MDITS :}

The researcher design Dynamic Knowledge Base systems as a key for the construction of dynamic system MDITS, which depends on much more intelligent databases as a major in the production and generation of Lesson's and instructions and Hint's Question's in addition to a set of sub-databases.

\section{RESUlTS AND DisCUSSION}

A. Answer to the First research questions: What are the different phases for building a dynamic e-tutor as intelligent Tutoring System?

The researcher reviewed some inteligent Tutoring systems of different educational stages, to the proposed building was in the light of the special education child Intelligent phase, at a much more elementary system (E-TUTOR MD_ITS) Math Station for Primary School and in which the researcher to identify and activate the role of the teacher and to ensure the benefit of experience in a dynamic manner to provide the intelligent system with lessons, all the questions, the appropriate guidance, and consistent with each child alone, 
the researcher have identified a set of procedural steps to be followed for the implementation of this order.

\section{Implementing E-Tutor as MD_ITS Model}

Programming language used in implementing MD_ITS in Personal home page language : PHP for the possibility of using the proposed inteligent Tutoring system, either through Offline (or) Online. To reach to the following model:

[1] Expert Model "knowledge extraction and representation", which was defined and draw experiences associated with fractures the unity of mathematics achievement of the objectives of the above-mentioned sources and studies on the lessons of that unit and rely on the direct experiences of the mathematics teachers in the pilot schools has been the construction of knowledge using Mysql.

[2] Student Model, to determine the student's knowledge of the topic of the educational system, fractions, and the proposed MD_ITS to provide intelligent problem of the child, the child in view of the solution of the education system, finding the child to the misconceptions of those answers.

[3] Tutorial Model, the role of proposed inteligent Tutoring system (MD_ITS) choose the lesson was appropriate for the child in the light of the level reached, depending on the number of times trying to the child answer or solving problem. So, the response model of ITS education offer the guidance Hints Help or assistance.

[4] User Interface, provide students and teachers with the manner in which the interaction is related to and interacts with the user's system and is sometimes called the unit of interaction with the user has been taken into account when designing the user interface for the specific nature of inteligent Tutoring system in terms of:

- $\quad$ The interaction between the user and the system.

- Control (who control, and when).

- $\quad$ Ease of use.

$-$

2. The E-Tutor Dynamic Math Intelligent Tutoring System (DM_ITS) for Primary School compared with some Traditional Software

Table 3 showed the analysis and the comparison of suggested Intelligent E-Tutor Software Versus The Traditional S/W on Math Teacher Attitudes

B. Answer To The Second Research Question: "What are the effectiveness of the Proposed E-tutor MD_ITS on the Direction of Mathematics Teachers Towards E-courses?

For the calculation of the homogeneity of the two groups and the measurement of trends in the pre-test group of the pilot and the experimental, the arithmetic mean was calculated, and the standard deviation, and the $\mathrm{F}$ ratio for groups in the pre-test measurement scale, as is clear from Table (4).

Table (4): The Significant Differences Between The Two Groups Attitudes In The Pilot Application For the Pre-Test Measurement Scale

\begin{tabular}{|c|c|c|c|c|c|}
\hline significance & F & the & degrees & Total & Source of \\
\hline
\end{tabular}

\begin{tabular}{c|c|c|c|c|c}
\hline \hline level & value & $\begin{array}{c}\text { average } \\
\text { value }\end{array}$ & $\begin{array}{c}\text { of } \\
\text { freedom }\end{array}$ & squares & variation \\
\hline \multirow{2}{*}{ insignificance } & \multirow{2}{*}{1.756} & 14.017 & 1 & 12,017 & $\begin{array}{c}\text { Among } \\
\text { the } \\
\text { groups }\end{array}$ \\
\cline { 3 - 6 } & & 7.980 & 28 & 233.45 & $\begin{array}{c}\text { Within } \\
\text { groups }\end{array}$ \\
\cline { 3 - 6 } & & & 29 & 245.467 & Total \\
\hline \hline
\end{tabular}

The results indicated that the statistical processing as shown in table (4) that the F ratio $(1,756)$ are not a function at the level of statistical significance $(0.01)$, and this meant that there was no statistical differences in function between the groups, which indicates the homogeneity of the levels of students for the measurement of trends before the experiment.

\section{Measurements of the Math Teacher Attitudes Towards Suggested MD_ITS:}

To verify the validity of the hypothesis which states that: " There is no statistically significant at the level of $(0.01)$ between the in the attitudes of teachers between the first pilot (using the Traditional Software) and the second experimental group (which used a dynamic intelligent Tutoring System), in favor of experimental group II".

To verify the effectiveness of the MD_ITS to change the attitudes of members of the second experimental group towards the use of electronic smart course in education, significant differences were calculated among the middle levels of the two members of the pilot, in the application of the dimensional measurement of trends, has been shown to achieve results with Table 5 .

In analyzing the results in table (5) clear trend higher average levels of teachers in the experimental group used the second dynamic intelligent Tutoring system when compared to the initial pilot group used Traditional Software, with an average degree of the second experimental group students (80.89), while the average score for students the first pilot (67.55), and amounted to "T." calculated $(4,065)$, and to disclose the value of " $t$ " in statistical table, we find it equal to (2.76) and thus be a "T." calculated the largest of the "t." in statistical table at the level of significance (0.01) and degrees of freedom 28 , that is, a statistical function.

Table (5): The Arithmetic Mean, Standard Deviation and The Value of "T" For The Average Degree of Post-Test (The Experimental Groups) Trend

\begin{tabular}{|c|c|c|c|c|c|c|}
\hline \multirow{2}{*}{$\begin{array}{l}\text { The } \\
\text { level } \\
\text { of } \\
\text { signif } \\
\text { icanc } \\
\text { e }\end{array}$} & \multirow{2}{*}{$\begin{array}{l}\text { "T." } \\
\text { Cal } \\
\text { cula } \\
\text { ted }\end{array}$} & \multicolumn{2}{|c|}{$\begin{array}{l}\text { Second } \\
\text { experimental group } \\
\text { (Dynamic } \\
\text { intelligent Tutoring } \\
\text { System) }\end{array}$} & \multicolumn{2}{|c|}{$\begin{array}{l}\text { The first pilot } \\
\text { (Traditional } \\
\text { Software) }\end{array}$} & \multirow{2}{*}{$\begin{array}{c}\text { Num } \\
\text { ber } \\
\text { of } \\
\text { mem } \\
\text { bers } \\
\text { of } \\
\text { each } \\
\text { grou } \\
\text { p }\end{array}$} \\
\hline & & $\begin{array}{c}\text { Standar } \\
\mathrm{d} \\
\text { deviati } \\
\text { on }\end{array}$ & $\begin{array}{l}\text { Arithmet } \\
\text { ic mean }\end{array}$ & $\begin{array}{l}\text { Stand } \\
\text { ard } \\
\text { deviat } \\
\text { ion }\end{array}$ & $\begin{array}{l}\text { Arith } \\
\text { metic } \\
\text { mean }\end{array}$ & \\
\hline Sig. & $\begin{array}{c}4.07 \\
5\end{array}$ & 4.12 & 80.89 & 9.33 & 67.55 & 5 \\
\hline
\end{tabular}

Thus being statistically significant in favor of the experimental group II which use (dynamic, inteligent Tutoring system), where the arithmetic mean with (80.89) by 
an increase from the first experimental group use(Traditional Software) is (13.34), and the hypothesis is accepted.

The research results agreed with more than a study including a study of Langer and colleagues (Langer \& et al, 1998), and a study of the (Razzaq, 2003) the results of which confirmed the importance of activating the intelligent software systems for smart positive results to both students and teachers, while the different study such as (Lane, 2006) with the view that where such systems have not achieved some of the benefits expected from building them, such as increased effectiveness and participation.

\section{INTERPRETATION OF THE RESULTS}

1) The researcher uses the method of teaching: which provide assistance to the child (Help), the firs method is Socratic Way used in the provision of guidance to the child (Hints), which encouraged teachers to use the system, convinced of his ability on the development of higher mental capacity of students.

2) The visual expressions included in the proposed intelligent system has played a big role in the development of innovative thinking, as many of the literature indicated that the innovative thinking requires a higher mental processes, and these processes are difficult to undertake without the visual expressions, especially in mathematics.

3) To provide students with the opportunity to sample enrichment activities which would contribute to the freedom of thought, and many questions to encourage the child to brainstorm and generate ideas relating to the subject, which has helped to increase the innovative thinking of students.

4) The proposed inteligent Tutoring system for the assessment manner provide report on the situation of the child where it can be for both the child and the teacher follow-up, giving the child a sense of self-confidence and ability to follow the scientific level, which affects the motivation to learn more from the development of innovative capabilities, also helps the teacher to track the level of students.

5) Interactive feature that characterizes the proposed MD_ITS, which encourages the child to be effective and positive. The students can construct problem solving, and its modification, and improvement after seeing the result of their interaction, which would help to know better based on the innovative (and this was confirmed by, Abdel-Halim, 1995).

All the features the previous system by activating the role of a teacher and involvement in the development of lessons and the questions and guidance, assistance and goodwill generated for the responsibility towards the students, and created a kind of competition among teachers to try to access to the most basic formulas, which would simplify the subject and therefore it was to benefit from their experiences as experts in area of specialization, also encouraged teachers to enter data and information, which in turn directly to the dynamics of knowledge bases built by the researcher.

\section{RESEARCH RECOMMENDATIONS}

In the light of the results of research, discussion and interpretation, some of the recommendations have been developed that may help in the development of building intelligent educational software systems, namely:

1) Preparation of training programs for staff members, especially the stages of the design and construction of inteligent Tutoring system in the light of methods and strategies of education and theories of teaching and learning.

2) Dependence on the construction of the proposed intelligent system (MD_ITS) and the findings of the researcher in the teaching methods and learning strategies.

3) Need to pay attention to a list of specifications and standards for the construction of Inteligent Tutoring system in the light of the characteristics of learners with each stage of the educational levels in order to build a inteligent Tutoring system for all stages.

4) Need to develop electronic Intelligent course through the Internet in light of the characteristics of education systems for each of the smart teacher and learner.

5) The need to involve teachers in the building of smart education systems, to ensure getting maximum benefit from their experiences as experts of the course, which they taught.

6) Benefit from the potential of education systems in the smart display different curricula, whether of a theoretical or practical, given the characteristic of these systems to provide an integrated environment of the media, which help make the process of teaching and learning experience tangible and the abstract is possible in the light of individual capabilities For Educators.

7) Need to pay attention to the employment of the latest techniques used inteligent Tutoring system to increase learner motivation and increase the incentive to have a study using Animated Agent mobile agent, the Life Agent in the provision of information or promotion and to provide assistance and guidance, in light of the results of this search.

8) Attention to design and build systems using the intelligent education programs and languages to ensure that freedom and do offer such systems, whether in the form of intelligent software (Off line) or learning via the Internet (On line), as applied in this research.

\section{THE PROPOSED RESEARCH}

Through the results of current research, and through review of previous studies have associated with it, could be proposed the following research:

1) Simulation of global research, which started in the design and construction of educational systems based on intelligent support and emotional guidance. 
2) Support the use of intelligent agent in the environment of inteligent Tutoring system of the various levels of education and to determine the effectiveness.

3) Diversification of educational materials that are applied to all stages of systems such as mathematics.

4) Build the ITS dealing with special needs individuals.

5) Discuss the effectiveness of the use of inteligent Tutoring system in the development of problem-solving skills, patterns of higher-order thinking critical and innovative thinking in the e-course.

6) Build Effective training programs for staff members to develop the skills of building inteligent Tutoring system in the light of the different strategies.

7) 10. Effective employment of inteligent Tutoring system in the development of trends towards different course.Conduct evaluation studies of educational systems in the smart areas that have been produced by intelligent systems.

8) The development of the employment of education systems across the Internet using a smart strategy of collaborative learning, students and the effectiveness of technology education.

\section{REFERENCES}

[1] Abu-Ata, Mohammed Kazem Khalil (2004): "The effectiveness of teaching programs based on artificial intelligence to develop the skills of computer use among students in technology education", unpublished MA thesis, University of Helwan, Faculty of Education, Department of Educational Technology.

[2] Al-Din, Iman Salah (1998): "the effectiveness of some structural changes in the production of educational software", Helwan University, Faculty of Education, PhD.

[3] AlFar, Ibrahim Abdul Wakil (2000): "Computer and the identification of the early twenty-first century", the Arab Thought House, Cairo, i 2.

[4] Altobjy, Hassan Hamad (1994): "list of technology terms," the Arab Organization for Education, Culture and Science Department of the techniques of education, Tunisia.

[5] Azmy, Rauf (1997): "the effectiveness of a proposed program in technology education for teachers in the same chapter," The Egyptian Association for the curricula, the Faculty of Education, Ain Shams University.

[6] Barber, Federico and J. Botti, Vicente, (2002): "A1 Past, Present and Failure", upgrade: The European online, magazine for it professional vol. 111, Issue no. 5, October

[7] Broadly, Intelligent Tutoring Systems (2000): Retrieved February 2, 2005, from: [http://www.aaai.org.AItopics/html/tutor.html] .

[8] EL-Sheikh, Eman, Mustafa (2002): "An Architecture for the generation of Intelligent Tutoring Systems from Resable Components and Knowledge- Based Systems" Diss. Ph.D. ,University of Michigan State, DAI. 0128 (2001-2004).

[9] Hendawi, Osama Saeed (2005): "the effectiveness of the proposal based on the media on the development of high-skilled students, the Division of thinking and technology education in the educational applications of the Internet, $\mathrm{PhD}$, Faculty of Education, University of Al-Azhar Badakkhlip.

[10] Honavar, Vasant (2005): "Principles of Artificial Intelligence" Anover View, Artificial Intelligence Research Laboratory, Department of Computer Science Tow state University, Ames Low a 50011, U.S.A, August.From:[http://www.cs.cmu.edu/ listen/pdf/its2002 RT plus w orkshop_final.pdf].
[11] Intelligent Tutoring Systems (2005): Retrieved February 2, 2008, from [http://www.aaai.org.AItopics/html/tutor.html] .

[12] Kerly, Alice; Ellis, Richard; Bull, Susan (2008): "CALM system: A Compensational Agent for Learning Modeling", Knowledge-Based systems, Vol. 21, Issue 3, April 2008, P. 238-246.

[13] Khamis, Mohammed Atieh, (2003): "The technology of education", Cairo, Dar-floor library.

[14] Lane, Chad (2006): "Intelligent Tutoring Systems: Prospects for Guided Practice and Efficient Learning", Research Scientist, Institute for Creative Technologies, University of Southern California, from [http://www.ict.usc.edu] July 27.

[15] Langer, I. Schewe; S. Headecke, C. Puppe and F. Rheinhardt, T. (1998): "Learning the Computer Evaluation of on Intelligent Tutoring System, Lehrstuhl Psychologies II Universities Wurzburg, Germany, European Journal of Medical Research 3 (1-2): 119-26, Feb 21.

[16] Ong, James. (2003): "Are Intelligent Tutoring System the Next Wave in Corporate Training Tech?, Journal of New England Technology. Retrieved February 2, 2005. from,

[http://www.masshightech.com/displayarticaledetail.asp?art id=6302 \&cat_id=1

[17] Ong, Jim and Ramachandran, Soumya (2000): "Intelligent Tutoring Systems: the what and the how", From [http://www.learningcircuits.org/2000/feb/ong/htm]

[18] Razzaq, Leena M. (2003): "Tutorial Dialog in an Equation Solving Intelligent Tutoring System", MS., Worcester Polytechnic Institute, Computer Science Dept., December. From [http://wpi.edu/pubs/ETD/Avariable/etd_0107104 155853/unrestricte d/irazzaq.pdf].

[19] Saleh, Magda Mahmoud (2002): "computer in the education of children," Dar Al-Fikr, Cairo, i 1

[20] Salem, Mohamed Abdel-Badie (2001): "artificial intelligence and computer systems expert," the audit Mustafa Ismail Shalabi, Cairo: Center for Open Education, Ain Shams University.

[21] Salem, Mohamed Abdel-Badie (2001): "artificial intelligence technology", a series of books in simplified scientific information, the fourth book, the printing press of the organs of the civil institution of scientific and business offices, Cairo, January 2001.

[22] Shehata, Gamal Abdel Nasser Mahmoud (2005): "the effectiveness of some of the strategies of artificial intelligence in the production of educational software on the development of innovative thinking," unpublished MA thesis, Faculty of Quality Education, Ain Shams University.

[23] Stankov, Slavomir; Rosic, Marko; Zitko , Branko; Grubisic، Ani (2007),TEX-Sys model for building intelligent Tutoring systems",Faculty of Natural Science, Mathematics and kinesiology, University of split, Teslina, 12, 21000 split, Croatia, Available online 14 November 2007.

[24] Stotter, Dick and Domeshek, Eric (2005): "Intelligent Tutoring System (ITS): Advanced Learing Technology for Enhancing War Fighter Performance, Ph.D., Stotter Henk Associates, Inc, San Mateo, CA and Boston, MA, Paper No. 2112.

[25] Wegerif, Rupert (2005): "Literature Review in Thinking Skills, Technology and Learning", Retrieved February 2, from [http://www.nestafuturelab.org/research/reviews/ts12.html]. 


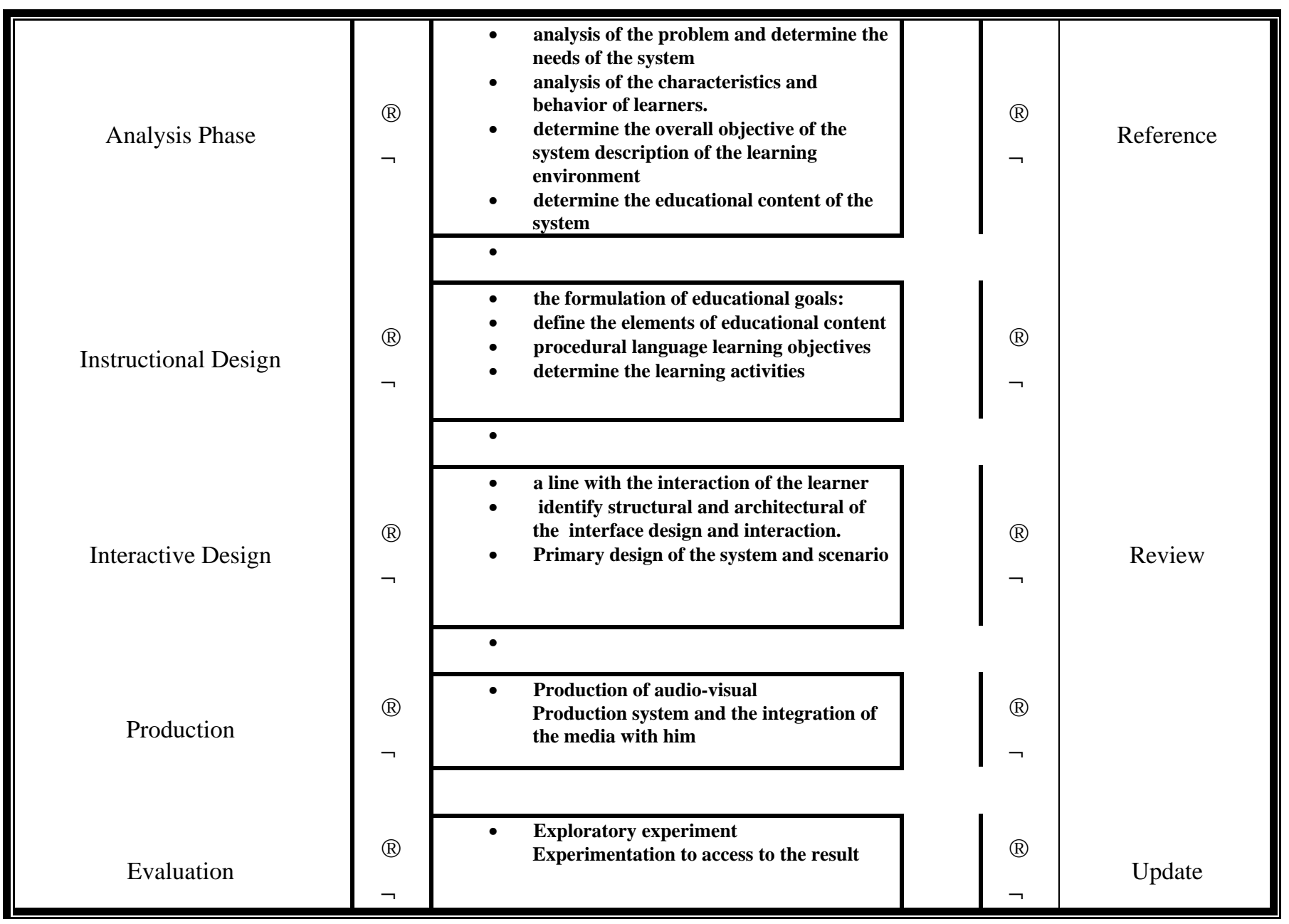

Figure (3): The Fogan Thai Model Explains The Computer Educational Programs Design

The following is the architectural components of E-Tutor MdD_ITS according to the proposed Instructional Design and its relationship as shown in Fig. (4)

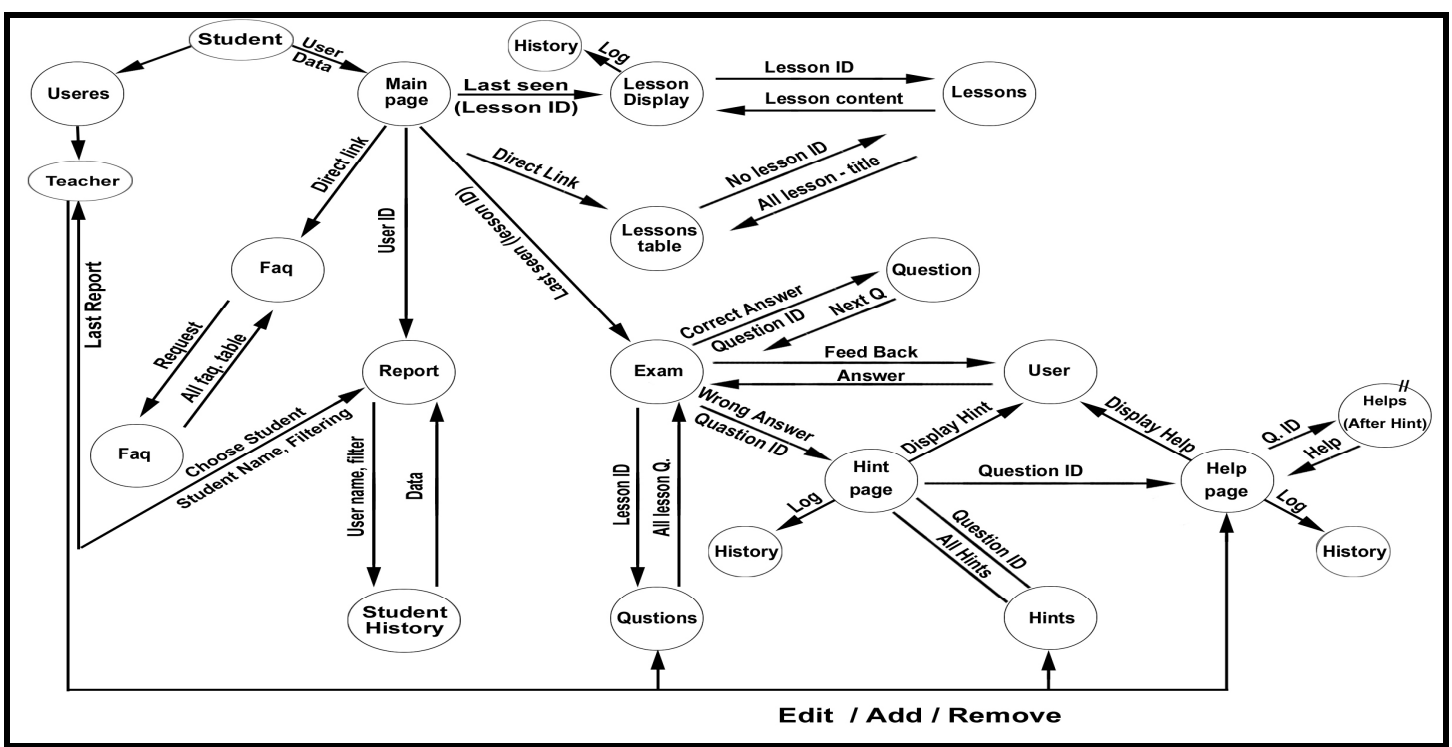

Figure (5): The Suggested Architecture of E-Tutor Math Dynamic Intelligent Tutoring System (MD_ITS) 


\begin{tabular}{|c|c|c|}
\hline The Differences & $\begin{array}{c}\text { Traditional Software For Math By } \\
\text { Ministry of Education }\end{array}$ & $\begin{array}{c}\text { The Proposed Intelligent System E-Tutor } \\
\text { MD_ITS }\end{array}$ \\
\hline $\begin{array}{l}\text { 1- The student has the } \\
\text { freedom to choose the } \\
\text { unit he want to study }\end{array}$ & $\begin{array}{l}\text { Math } \\
\text { The main screen display that the student can } \\
\text { only choose the unit he want to study. }\end{array}$ & $\begin{array}{l}\text { The main screen give the student the freedom and a } \\
\text { range of choices such: } \\
\text { - Current Topic, Topic List, Exam } \\
\text { - Reports, Buttons Guide }\end{array}$ \\
\hline $\begin{array}{l}\text { 2- Tracking the child } \\
\text { level }\end{array}$ & $\begin{array}{l}\text { - Traditional software does not allow to } \\
\text { track the level of the child }\end{array}$ & - Both student and teacher can join together and working \\
\hline $\begin{array}{l}\text { - The possibility of } \\
\text { adding new lessons } \\
\text { by teachers }\end{array}$ & $\begin{array}{l}\text { Messon } 3 \\
\text { Ien, hundriped } \\
\text { and thousund } \\
\text { - There is no possibility of adding new } \\
\text { courses (Static Design). }\end{array}$ & $\begin{array}{l}\text { - The possibility of adding lessons by teacher to } \\
\text { database of (a dynamic system), which could be appear } \\
\text { as soon as the child press button of Topic List. }\end{array}$ \\
\hline
\end{tabular}




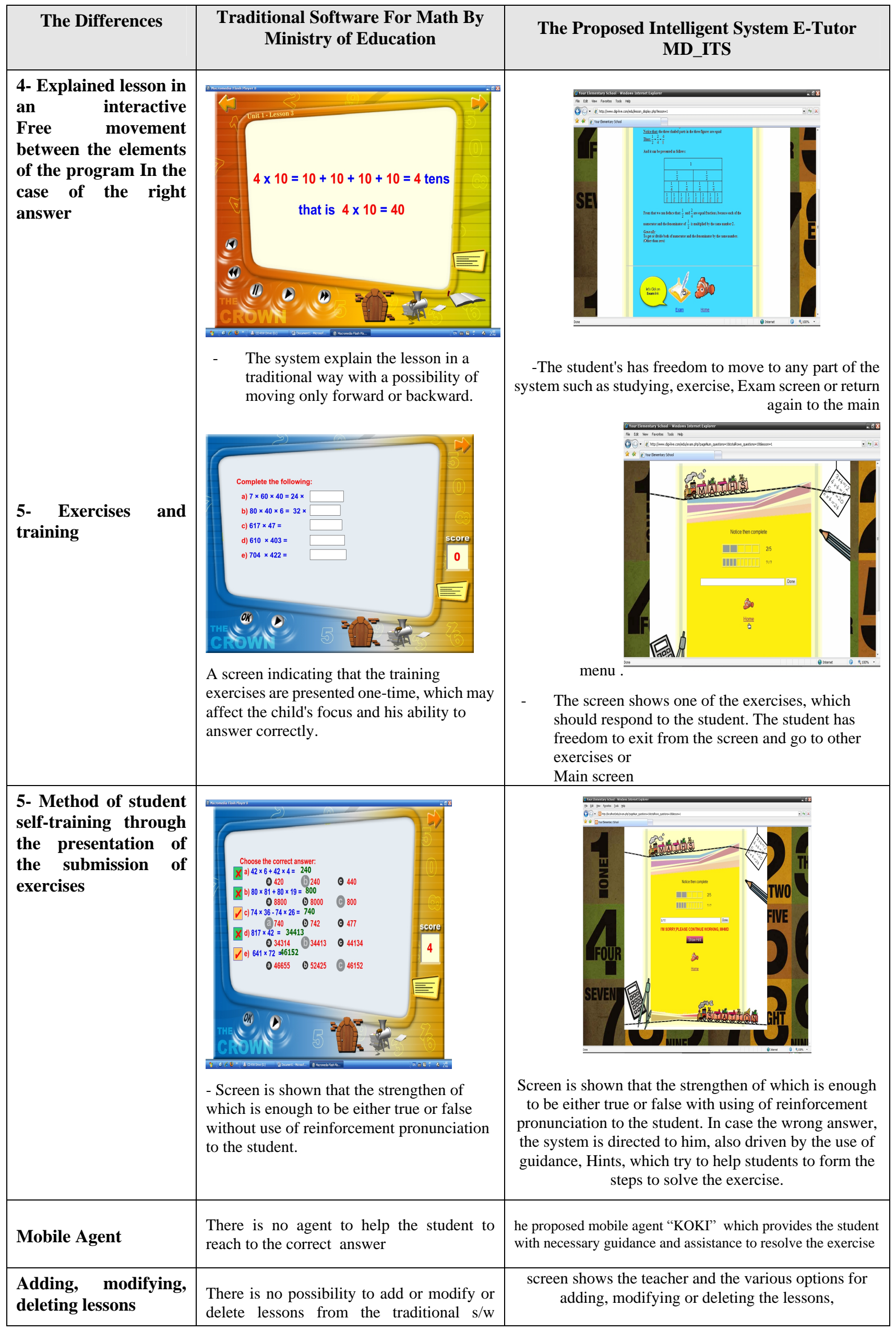




\begin{tabular}{|c|c|c|}
\hline The Differences & $\begin{array}{l}\text { Traditional Software For Math By } \\
\text { Ministry of Education }\end{array}$ & $\begin{array}{c}\text { The Proposed Intelligent System E-Tutor } \\
\text { MD_ITS }\end{array}$ \\
\hline & program & 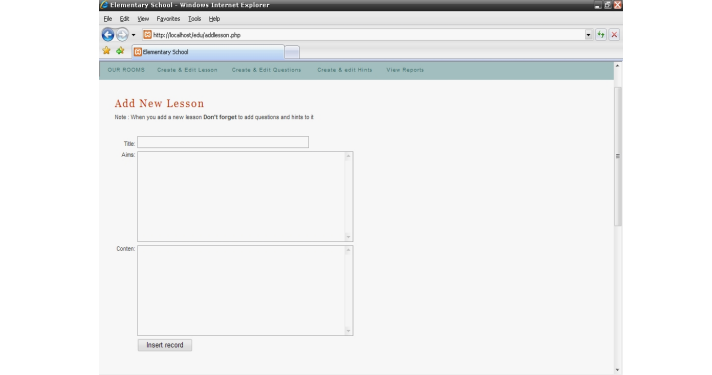 \\
\hline $\begin{array}{l}\text { Assistance } \quad \text { and } \\
\text { guidance }\end{array}$ & 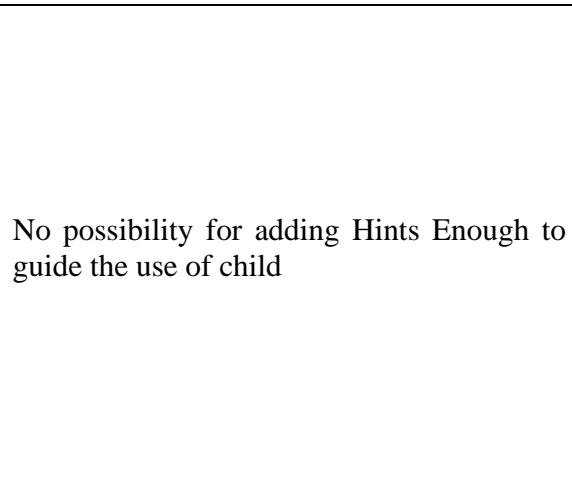 & $\begin{array}{l}\text { screen shows the teacher can add a new Hints for lesson } \\
\text { explanation }\end{array}$ \\
\hline
\end{tabular}

